\title{
CFP Regimen
}

National Cancer Institute

\section{Source}

National Cancer Institute. CFP Regimen. NCI Thesaurus. Code C9548.

A chemotherapy regimen consisting of cyclophosphamide, fluorouracil, and prednisone that may be used in the treatment of advanced breast cancer. 